Im „Journal Club“ werden Originalarbeiten aus der internationalen Fachliteratur referiert und kommentiert.

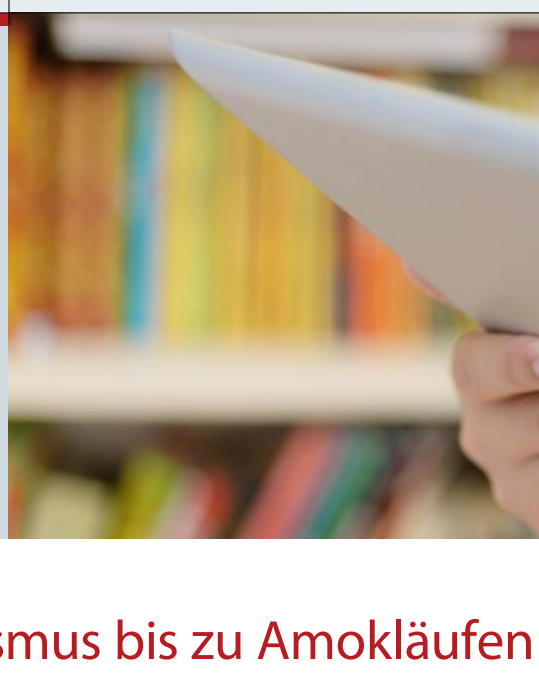

\section{Anschläge: Von Terrorismus bis zu Amokläufen}

\author{
Züchten schlagende Eltern Terroristen heran? Warum sind Amokläufer und \\ Attentäter nahezu immer junge Männer? Der Kriminologe Christian Pfeiffer \\ führt das auf evolutionäre und kulturelle Gründe zurück.
}

$R^{\mathrm{i} i}$ az Khan A. in Würzburg, Adel K. und Abdel Malik P. in Rouen oder Mohamed L. in Nizza - praktisch immer sind es Männer, die Terroranschläge verüben, wie in den zurückliegenden Wochen in Europa. Warum?

Für Professor Christian Pfeiffer, ehemals Leiter des Kriminologischen Forschungsinstitutes Niedersachsen in Hannover (KFN), liegen die Dinge auf der Hand: Dass fast immer die Männer die Gewalttäter sind, begründet er mit der Rolle der Männer in der kulturellen Evolution der Menschheit. Dass aber dieses Erbe in manchen Ländern gut gehandhabt wird und in anderen nicht, habe andere Gründe. „Länder, in denen die körperliche Züchtigung in Schulen und Familien verboten ist, haben ein deutlich geringeres Problem mit Gewalttätern“, sagt Pfeiffer zur „Ärzte Zeitung“/ Springer Medizin.

Warum vor allem muslimische junge Männer mit Messern, mit Schusswaffen, mit einer Axt, mit einem Bombengürtel am Leib oder im Führerhaus eines LKW auf ihre Mitmenschen losgehen und Dutzende, ja Hunderte mitleidlos töten, wird zum Beispiel mit Kränkungen begründet.

\section{Fortpflanzung der Kämpfertypen}

Diese könnten Täter nicht anders bewältigen als durch Gewalt, die sie über die Medien auch noch bekannt macht und so ihrer Eitelkeit dient. So argumentiert zum Beispiel der Psychoanalytiker Martin Altmeyer im jüngsten SPIEGEL. Pfeiffer hat eine andere Erklärung: 95 von 100 Strafgefangenen in Deutschland sind Männer, bestätigt der Kriminologe. Kein Wunder, sagt er, denn die „Evolution ist die Mutter der Mackerkultur". In ihrem Verlauf konnten sich die Kämpfertypen eben eher fortpflanzen. Die Frauen dagegen entwickelten eine Kultur des Behütens und der Kommunikation und tradierten diese Eigenschaften.

\section{Männer: Wohin mit der innenwohnenden Gewalt?}

Ihr Erbe werde heute eher gebraucht als das der Männer, deren Überschuss an Gewalt heute zivilisatorisch ins Leere laufe, meint Pfeiffer. Sportwettkämpfe oder Ballerspiele am PC genügten nicht mehr, um die Gewaltbereitschaft abzuleiten. So stünden die Männer da mit ihrer Wut und wissen nicht wohin - Gewaltausbrüche programmiert. Selbst in der Feuerwehr oder bei der Polizei können sie nicht mehr ihre Aggressionen ableiten. Längst zählen auch hier immer häufiger die Soft Skills, sagt Pfeiffer zur „Ärzte Zeitung“/Springer Medizin: „50\% des Polizei-Nachwuchses sind Frauen.“

Diesem Druck der Evolution sei nur mit eine Kultur der gewaltfreien Erziehung beizukommen, so Pfeiffer. Männer, die als Kinder geschlagen wurden, setzen tendenziell Gewalt fort, sagt er. „Wo aber die Kinder nicht geschlagen werden, sinkt die Zahl der Gewalttaten." Die Studienergebnisse $\mathrm{zu}$ dieser These seien „faszinierend“.

Befragungen unter deutschen Jugendlichen ergaben, dass solche, die angaben, liebevoll erzogen worden $\mathrm{zu}$ sein, $\mathrm{zu}$
$5,9 \%$ an Gewalttaten beteiligt waren, Jugendliche dagegen, die wenig Liebe und zu Hause viel Gewalt erfahren hatten, waren zu $39 \%$ an Gewalttaten beteiligt. Auch denkt mit $48 \%$ fast die Hälfte dieser Jugendlichen an Selbstmord. Unter den Jugendlichen mit einer liebevollen Erziehung waren es nur 7\%.

\section{Gewalt in der Kindheit bringt öfters Terroristen hervor}

1970 war Schweden das erste Land der Welt, das die körperliche Züchtigung durch Eltern verbot. „Bis heute sind 50 Länder weltweit diesem Vorbild gefolgt", so Pfeiffer. In Europa zum Beispiel Österreich oder die skandinavischen Länder. Bis heute gehören aber die USA, Frankreich - „ein Volk voller Wut“, sagt Pfeiffer - Polen oder England nicht dazu. „Seit im Jahr 2000 das Schlagen im Elternhaus in Deutschland gesetzlich verboten wurde, verzeichnen wir einen Rückgang bei den Tötungsdelikten im Land von $40 \%$ ", berichtet Pfeiffer. Auch bei den muslimischen Migranten, die aus Ländern kommen, wo das Schlagen im Elternhaus erlaubt ist, wachse die Einsicht, dass die Züchtigung der Kinder übel sei, so Pfeiffer. Nach Studien des KFN sei die Gewaltbereitschaft türkischstämmiger Jugendlicher in Deutschland infolgedessen von 32\% im Jahr 1998 auf 13\% im Jahr 2015 zurückgegangen. Gewaltfreie Erziehung lohne sich auch für die Eltern, sagt Pfeiffer: „Denn irgendwann, wenn die Eltern alt sind, schlagen die Kinder zurück auf die eine oder andere Weise. Kinder, die nie geschlagen wurden, tun das nicht."

Christian Beneker 